\title{
75 years of leadership in the Canadian Anesthesiologists' Society: a gender analysis
}

\author{
Gianni R. Lorello, BSc, MD, MSc (Med Ed), CIP, FRCPC (1) - Alana M. Flexman, MD, FRCPC
}

Received: 18 March 2019/Revised: 25 March 2019/Accepted: 25 March 2019/Published online: 2 April 2019

(C) Canadian Anesthesiologists' Society 2019

\section{To the Editor,}

Historically, men have served in the vast majority of leadership positions in medical societies, including those in anesthesiology. Despite increases in the number of women physicians in practice over the past few decades, women remain significantly underrepresented in positions of leadership and influence. ${ }^{1}$ The purpose of this analysis was to examine the participation of women in leadership at the Canadian Anesthesiologists' Society (CAS), specifically determining the proportion of women presidents over time.

In this retrospective, cross-sectional analysis of previous presidents of the CAS, an overwhelming proportion have been men. The CAS celebrated its 75th anniversary in 2018, and since its inception in 1943, 95.5\% (64/67) of its presidents have been men, compared with $4.5 \%$ (3/67) women. The first woman to serve as president of the CAS, Dr. Angela Enright, was elected in 1994 and remained the only woman to serve as president until 2012. Nevertheless,

G. R. Lorello, BSc, MD, MSc (Med Ed), CIP, FRCPC ( $\square)$ Department of Anesthesia, University of Toronto, Toronto, ON, Canada

e-mail: Gianni.Lorello@uhn.ca

Toronto Western Hospital, University Health Network, Toronto, ON, Canada

The Wilson Centre, University Health Network, Toronto, ON, Canada

\author{
A. M. Flexman, MD, FRCPC \\ Vancouver General Hospital - Department of Anesthesiology, \\ Vancouver, BC, Canada
}

Department of Anesthesiology, Pharmacology and Therapeutics, The University of British Columbia, Vancouver, BC, Canada two of the most recent three presidents have been women. The current CAS vice-president is also a woman, and she will ascend to the president's role in 2020 .

This analysis shows that women have historically been underrepresented in the CAS' leadership, just as they have been in the national awards given by CAS. ${ }^{2}$ Nevertheless, we are encouraged by the uptick in women CAS presidents over the last seven years. We reiterate the importance of representing women in any specialty and, along with Drs McKeen, Bryson, and Lundine, ${ }^{3}$ we are "taking the pledge" with the discourse around gender disparity, promoting gender diversity, and researching individual and organizational factors to address the underrepresentation of women in anesthesiology and in leadership positions. Medical leadership is in need of a fundamental cultural shift towards greater inclusion of all physicians regardless of their gender, race, or sexuality.

The 2018 \#BeEthical white paper by Dr. Julie K. Silver from the Department of Physical Medicine and Rehabilitation at Harvard Medical School has advocated for healthcare leaders to use a systematic process and specific metrics to evaluate disparities. ${ }^{4}$ We commend the CAS for taking the initiative in supporting women in anesthesiology and note the recent formation of its Diversity, Equity, and Inclusion Working Group. ${ }^{3}$ Individuals in leadership positions must deliberately support both men and women towards achieving leadership positions. We are encouraged both by the advent of key gender strategies within the CAS and by having objective data upon which to evaluate these initiatives. Although women have largely been absent in the leadership of the CAS until relatively recently, we are optimistic that the future will tell a different story.

Conflicts of interest None declared. 
Editorial responsibility This submission was handled by Dr. Hilary P. Grocott, Editor-in-Chief, Canadian Journal of Anesthesia.

\section{References}

1. Silver JK, Ghalib R, Poorman JA, et al. Analysis of gender equity in leadership of physician-focused medical specialty societies, 2008-2017. JAMA Intern Med 2019; 179: 433-5.

2. Mottiar M. Because it's 2018: women in Canadian anesthesiology. Can J Anesth 2018; 65: 453-4.
3. McKeen DM, Bryson GL, Lundine J. Underrepresentation of women in Canadian Journal of Anesthesia publications: no surprise-take the pledge! Can J Anesth 2019; DOI: https://doi. org/10.1007/s12630-019-01329-4.

4. Silver JK, Slocum CS, Bank AM, et al. Where are the women? The underrepresentation of women physicians among recognition award recipients from medical specialty societies. PM R 2017; 9: 804-15.

Publisher's Note Springer Nature remains neutral with regard to jurisdictional claims in published maps and institutional affiliations. 